\title{
IMPLEMENTASI K-MEANS CLUSHTERING DALAM MENGELOMPOKKAN MINAT MEMBACA PENDUDUK MENURUT WILAYAH
}

\author{
Mhd Yuda Rizki ${ }^{1}$, Siti Maysaroh ${ }^{2}$, dan Agus Perdana Windarto ${ }^{3}$ \\ ${ }^{1,2,3}$ Prodi Sistem Informasi STIKOM TUNAS BANGSA Pematangsiantar,Indonesia \\ Ryuda1014@gmail.com¹, Maysarohsaragih2808@gmail.com², \\ Agus.perdana@amiktunasbangsa.ac.id ${ }^{3}$
}

\begin{abstract}
Abstrak
Membaca adalah salah satu kegiatan yang sangat bermanfaat dan membaca dapat menambah dan memperluas wawasan dan ilmu pengetahuan yang sudah kita miliki.Di era teknologi ini banyak sekali masyarakat yang sudah tidak peduli lagi dengan membaca karena beberapa faktor terutama rasa malas yang ada di dalam diri.Penelitian ini membahas tentang "Implementasi K-Means Clushtering Dalam Mengelompokkan Minat Membaca Penduduk Menurut Wilayah".Data di dalam penelitian ini di ambil dari sebuah website pemerintah yakni BPS(Badan Pusat Statistik) www.bps.go.id. Peneliti menggunakan algoritma K-Means dan mengelompokkannya menjadi -2 clushter atau kelompok yaitu clushter tingkat tinggi(C1) dan rendah $(\mathrm{C} 2)$.Terdapat -33 Provinsi di Indonesia di dalam penelitian ini.Hasil dari penelitian terdapat -12 Provinsi menduduki posisi tingkat tinggi dan 21 Provinsi menduduki posisi clushter tingkat rendah.Diharapkan dengan dilakukannya penelitiaan ini dapat menjadi masukan dan informasi kepada pemerintah setiap wilayah agar melakukan sosialisasi atau kegiatan yang dapat meningkatkan minat baca penduduk tiap wilayah terutama pada wilayah yang menduduki posisi tingkat rendah(C2).
\end{abstract}

Kata Kunci: Data Mining, K-Means, Clushtering, Membaca

\begin{abstract}
Reading is one of the activities that is very useful and reading can add and broaden the horizons and knowledge that we already have. In this technological era many people no longer care about reading because of several factors, especially the feeling of laziness that is within. It discusses "Implementation of K-Means Clushtering in Grouping Interest in Reading Population by Region". The data in this study was taken from a government website namely BPS (Central Statistics Agency) www.bps.go.id.Researchers used the K-Means algorithm and grouping them into -2 clushter or groups of high-level (C1) and low-level (C2) clushers. There are -33 Provinces in Indonesia in this study. low level. Hopefully this research can be input and information to every government regions to conduct socialization or activities that can increase the interest in reading the population of each region, especially in areas that occupy low-level positions (C2).
\end{abstract}

Keywords: Data Mining, K-Means, Clushtering, Reading.

\section{Pendahuluan}

Membaca adalah salah satu kegiatan yang sangat bermanfaat dan membaca dapat menambah dan memperluas wawasan dan ilmu pengetahuan yang sudah kita miliki.Di 
era teknologi ini banyak sekali masyarakat yang sudah tidak peduli lagi dengan membaca karena beberapa faktor terutama rasa malas yang ada di dalam diri.Dilihat dari mayoritas mahasiswa menurut (Farida, 2012) Membaca ternyata bukanlah kegiatan yang dilakukan setiap hari, terbukti dengan hasil survey yang menyatakan nihil alias tidak seorangpun mahasiswa yang membaca setiap hari. Kondisi ini tentu saja sangat memprihatinkan mengingat membaca seharusnya menjadi "reading habit" bagi mahasiswa.Penelitian ini membahas tentang "Implementasi K-Means Clushtering Dalam Mengelompokkan Minat Membaca Penduduk Menurut Wilayah".Data di dalam penelitian ini di ambil dari sebuah website pemerintah yakni BPS(Badan Pusat Statistik) www.bps.go.id. Peneliti menggunakan algoritma K-Means dan mengelompokkannya menjadi -2 clushter atau kelompok yaitu clushter tingkat tinggi(C1) dan rendah (C2).Terdapat -33 Provinsi di Indonesia di dalam penelitian ini.Hasil dari penelitian terdapat -12 Provinsi menduduki posisi tingkat tinggi dan -21 Provinsi menduduki posisi clushter tingkat rendah.Diharapkan dengan dilakukannya penelitiaan ini dapat menjadi masukan dan informasi kepada pemerintah setiap wilayah agar melakukan sosialisasi atau kegiatan yang dapat meningkatkan minat baca penduduk tiap wilayah terutama pada wilayah yang menduduki posisi tingkat rendah(C2).

\section{Tinjauan Pustaka}

\section{A. Data Mining}

Istilah data mining mulai dikenal sejak tahun 1990, ketika pekerjaan pemanfaatan data menjadi sesuatu yang penting dalam berbagai bidang, mulai dari bidang akademik, bisnis hingga edisi. Munculnya data mining didasarkan pada jumlah data yang tersimpan dalam basis data semakin besar. Dalam berbagai literatur, teori-teori pada data mining sudah ada sejak lama seperti antara lain K-Means Clustering dan text mining. Data mining disebut juga dengan kno wledge discovery in database (KDD) ataupun pattern recognition. Istilah KDD atau disebut penemuan pengetahuan data karena tujuan utama data mining adalah untuk memanfaatkan data dalam basis data dengan mengolahnya sehingga menghasilkan informasi baru yang berguna. Sedangkan istilah pattern recognition atau disebut pengenalan pola mempunyai tujuan pengetahuan yang akan digali dari dalam bongkahan data yang sedang dihadapi (Iin Parlina, Agus Perdana Windarto, Anjar Wanto, 2018)

\section{B. Cluhtering}

Clustering atau klasifikasi adalah metode yang digunakan untuk membagi rangkaian data menjadi beberapa group berdasarkan kesamaan-kesamaan yang telah ditentukan sebelumnya. Cluster adalah sekelompok atau sekumpulan objek-objek data yang similar satu sama lain dalam cluster yang sama dan dissimilar terhadap objekobjek yang berbeda cluster. Objek akan dikelomokkan ke dalam satu atau lebih cluster sehingga objek-objek yang berada dalam satu cluster akan mempunyai kesamaan yang tinggi antara satu dengan yang lainnya (Metisen \& Sari, 2015).

\section{c. K-Means}

K-Means adalah metode clustering berbasis jarak yang membagi data ke dalam sejumlah cluster dan algoritma ini hanya bekerja pada atribut numeric. Algoritma $K$ Means termasuk partitioning clustering yang memisahkan data ke $k$ daerah bagian yang terpisah. Algoritma $K$-Means sangat terkenal karena kemudahan dan kemampuannya untuk mengcluster data yang besar dan data outlier dengan sangat cepat.Dalam algoritma $K$-Means, setiap data harus termasuk ke cluster tertentu dan bisa dimungkinkan bagi setiap data yang termasuk cluster tertentu pada suatu tahapan proses, pada tahapan berikutnya berpindah ke cluster lainnya (Metisen \& Sari, 2015).

\section{Metodologi Penelitian}

Dalam penelitian ini metode yang digunakan yaitu metode Data Mining sebagai berikut (Sadewo et al., 2017) :
(a) Tahap pengumpulan data,

(b) Tahap pengolahan data, 
(c) Tahap Clustering dan

(d) Tahap Analisis

\section{A. Tahap Pengumpulan Data}

Dalam Penelitian ini sumber data penelitian diperoleh dari sebuah website penyedia data sttistik yakni www.bps.go.id.Data terdiri dari -33 Provinsi di Indonesia. Terdapat -2 clushter yakni tingkat tinggi $(\mathrm{C} 1)$ dan rendah $(\mathrm{C} 2)$.

\section{B. Tahap Pengolahan Data}

Data yang telah diperolah akan diolah terlebih dahulu untuk dapat diclustering. Sebelumnya data sudah di normalisasikan dari atribut perkotaan dan pedesaan dari data asli sehingga, data setiap provinsi akan dijumlah setiap aspeknya sehingga pada tahapan ini sudah diperoleh perhitungan nilai yang akan diproses pada tahap clustering.

\section{Tahap Clustering}

Clustering merupakan klasifikasi tanpa pengawasan dan merupakan proses partisi sekumpulan objek data dari satu set menjadi beberapa kelas. Hal ini dapat dilakukan dengan menerapkan berbagai persamaan dan langkah-langkah mengenai jarak algoritma, yaitu dengan Euclidean Distance. Analisis kluster ialah metode yang dipakai untuk membagi rangkaian data menjadi beberapa grup berdasarkan kesamaan-kesamaan yang telah ditentukan sebelumnya.Dalam menentukan cluster berdasarkan data yang telah tersedia.

\section{Tahap Analisis}

Pada tahapan ini dilakukan analisis data.Data yang diperoleh diolah dengan menggunakan perhitungan bobot dari tiap indeks dengan menentukan centroid data dari setiap proses dan akanmenghasilkan suatu pola clushter.

\section{Analisi Dan Pembahasan}

Data akan di proses dengan menentukan centroid data terlebih dahulu lalu akan di clushter.

\begin{tabular}{|c|c|c|c|c|c|}
\hline \multirow[t]{2}{*}{ NO } & \multirow[t]{2}{*}{ Provinsi } & \multicolumn{4}{|c|}{$\begin{array}{c}\text { Proporsi Penduduk Berumur } 5 \text { Tahun ke Atas yang Membaca } \\
\text { (Baik Cetak Maupun Elektronik) Selama Seminggu Terakhir } \\
\text { menurut Provinsi, Jenis Bacaan, dan Tipe Daerah, } 2018\end{array}$} \\
\hline & & surat kabar & buku cerita & pelajaran sekolah & pengetahuan \\
\hline 1 & Aceh & 29,7073 & 14,0153 & 29,2699 & 25,9120 \\
\hline 2 & Sumatera Utara & 19,5214 & 11,1322 & 29,7892 & 23,9636 \\
\hline 3 & Sumatera Barat & 13,8884 & 9,7352 & 25,0985 & 23,5887 \\
\hline 4 & Jambi & 22,4544 & 9,8410 & 23,4542 & 21,8098 \\
\hline 5 & Sumatera Selatan & 16,6058 & 8,4948 & 25,4152 & 20,2537 \\
\hline 6 & Bengkulu & 18,3236 & 9,7531 & 29,1942 & 22,0459 \\
\hline 7 & Lampung & 15,2539 & 8,1016 & 22,9609 & 17,1420 \\
\hline 8 & Kepulauan Bangka Belitung & 19,1643 & 8,7687 & 20,8145 & 19,9087 \\
\hline 9 & Kepulauan Riau & 20,3587 & 11,7139 & 29,2339 & 21,5592 \\
\hline 10 & DKI Jakarta & 15,6598 & 7,5156 & 12,5742 & 13,2347 \\
\hline 11 & Jawa Barat & 15,9530 & 11,4556 & 26,0086 & 20,8385 \\
\hline 12 & Jawa Tengah & 13,3500 & 8,7576 & 23,8768 & 17,7853 \\
\hline 13 & DI Yogyakarta & 30,8766 & 16,3217 & 27,5575 & 25,0740 \\
\hline 14 & Jawa Timur & 16,9374 & 10,7777 & 24,1904 & 21,5292 \\
\hline 15 & Banten & 13,2148 & 11,8380 & 24,4185 & 21,0826 \\
\hline 16 & Bali & 19,2023 & 10,5297 & 25,3598 & 23,3886 \\
\hline 17 & Nusa Tenggara Barat & 8,4456 & 10,0895 & 27,8192 & 21,2689 \\
\hline
\end{tabular}




\begin{tabular}{|c|c|c|c|c|c|}
\hline \multirow[t]{2}{*}{ NO } & \multirow[t]{2}{*}{ Provinsi } & \multicolumn{4}{|c|}{$\begin{array}{c}\text { Proporsi Penduduk Berumur } 5 \text { Tahun ke Atas yang Membaca } \\
\text { (Baik Cetak Maupun Elektronik) Selama Seminggu Terakhir } \\
\text { menurut Provinsi, Jenis Bacaan, dan Tipe Daerah, } 2018\end{array}$} \\
\hline & & surat kabar & buku cerita & pelajaran sekolah & pengetahuan \\
\hline 18 & Nusa Tenggara Timur & 14,0070 & 13,5336 & 32,3904 & 25,4110 \\
\hline 19 & Kalimantan Barat & 16,0679 & 11,0129 & 26,2958 & 20,1092 \\
\hline 20 & Kalimantan Tengah & 19,9178 & 12,7428 & 25,3305 & 22,2356 \\
\hline 21 & Kalimantan Selatan & 14,8464 & 10,9727 & 26,8760 & 20,6319 \\
\hline 22 & Kalimantan Timur & 20,9379 & 13,5211 & 26,8550 & 22,7146 \\
\hline 23 & Kalimantan Utara & 15,3698 & 9,0029 & 25,9828 & 19,7071 \\
\hline 24 & Sulawesi Utara & 19,4282 & 6,9188 & 22,8298 & 18,5365 \\
\hline 25 & Sulawesi Tengah & 13,8058 & 9,3120 & 25,3431 & 22,8304 \\
\hline 26 & Sulawesi Selatan & 17,9456 & 9,0289 & 26,3153 & 24,0274 \\
\hline 27 & Sulawesi Tenggara & 11,3707 & 6,8166 & 27,8044 & 18,7653 \\
\hline 28 & Gorontalo & 13,2727 & 11,4663 & 26,0731 & 17,0513 \\
\hline 29 & Sulawesi Barat & 13,1303 & 10,7653 & 27,1014 & 15,0427 \\
\hline 30 & Maluku & 9,0148 & 8,2610 & 29,8018 & 23,0982 \\
\hline 31 & Maluku Utara & 20,8264 & 8,8212 & 31,4883 & 25,1614 \\
\hline 32 & Papua Barat & 15,0724 & 7,4663 & 23,1000 & 19,0316 \\
\hline 33 & Papua & 14,4619 & 5,8184 & 21,6873 & 16,0418 \\
\hline
\end{tabular}

Selanjutnya adalah menentukan centroid data awal dari data yang telah diperoleh ke dalam
2 clushter yakni clushter tingkat tinggi (C1) dan clushter tingkat rendah (C2).

TABEL 2. CENTOID DATA AwaL

\begin{tabular}{ccccc}
\hline & $\mathrm{a}$ & $\mathrm{b}$ & $\mathrm{c}$ & $\mathrm{d}$ \\
\hline $\mathrm{c} 1$ & 30,8766 & 16,3217 & 32,3904 & 25,9120 \\
$\mathrm{c} 2$ & 8,4456 & 5,8184 & 12,5742 & 13,2347 \\
\hline
\end{tabular}

Keterangan :

$\mathrm{A}=$ Surat Kabar

$\mathrm{B}=$ Buku Cerita

$$
\begin{aligned}
& \mathrm{C}=\text { Pelajaran Sekolah } \\
& \mathrm{D}=\text { Pengetahuan }
\end{aligned}
$$

TABEL 3

\begin{tabular}{|c|c|c|c|c|c|c|c|c|}
\hline \multirow[t]{2}{*}{ NO } & \multirow[t]{2}{*}{ Provinsi } & \multicolumn{4}{|c|}{$\begin{array}{c}\text { Proporsi Penduduk Berumur } 5 \text { Tahun ke Atas yang } \\
\text { Membaca (Baik Cetak Maupun Elektronik) Selama } \\
\text { Seminggu Terakhir menurut Provinsi, Jenis Bacaan, } \\
\text { dan Tipe Daerah, } 2018\end{array}$} & \multirow[b]{2}{*}{$\mathrm{c} 1$} & \multirow[b]{2}{*}{$\mathrm{c} 2$} & \multirow[b]{2}{*}{ jp } \\
\hline & & surat kabar & $\begin{array}{l}\text { buku } \\
\text { cerita }\end{array}$ & $\begin{array}{c}\text { pelajaran } \\
\text { sekolah }\end{array}$ & pengetahuan & & & \\
\hline 1 & Aceh & 29,7073 & 14,0153 & 29,2699 & 25,9120 & 4,0527 & 30,9630 & 4,0527 \\
\hline 2 & Sumatera Utara & 19,5214 & 11,1322 & 29,7892 & 23,9636 & 12,9009 & 23,7144 & 12,9009 \\
\hline 3 & Sumatera Barat & 13,8884 & 9,7352 & 25,0985 & 23,5887 & 19,7623 & 17,5792 & 17,5792 \\
\hline 4 & Jambi & 22,4544 & 9,8410 & 23,4542 & 21,8098 & 14,4782 & 20,1080 & 14,4782 \\
\hline 5 & Sumatera Selatan & 16,6058 & 8,4948 & 25,4152 & 20,2537 & 18,5899 & 16,9679 & 16,9679 \\
\hline
\end{tabular}

PROSES ITERASI -1 


\begin{tabular}{|c|c|c|c|c|c|c|c|c|}
\hline 6 & Bengkulu & 18,3236 & 9,7531 & 29,1942 & 22,0459 & 15,0295 & 21,6083 & 15,0295 \\
\hline 7 & $\begin{array}{l}\text { Lampung } \\
\text { Kepulauan Bangka }\end{array}$ & 15,2539 & 8,1016 & 22,9609 & 17,1420 & 21,8511 & 13,2179 & 13,2179 \\
\hline 8 & Belitung & 19,1643 & 8,7687 & 20,8145 & 19,9087 & 19,0857 & 15,3636 & 15,3636 \\
\hline 9 & Kepulauan Riau & 20,3587 & 11,7139 & 29,2339 & 21,5592 & 12,6795 & 22,8805 & 12,6795 \\
\hline 10 & DKI Jakarta & 15,6598 & 7,5156 & 12,5742 & 13,2347 & 29,3682 & 7,4112 & 7,4112 \\
\hline 11 & Jawa Barat & 15,9530 & 11,4556 & 26,0086 & 20,8385 & 17,6879 & 18,0676 & 17,6879 \\
\hline 12 & Jawa Tengah & 13,3500 & 8,7576 & 23,8768 & 17,7853 & 22,4260 & 13,4591 & 13,4591 \\
\hline 13 & DI Yogyakarta & 30,8766 & 16,3217 & 27,5575 & 25,0740 & 4,9050 & 31,2751 & 4,9050 \\
\hline 14 & Jawa Timur & 16,9374 & 10,7777 & 24,1904 & 21,5292 & 17,6490 & 17,3332 & 17,3332 \\
\hline 15 & Banten & 13,2148 & 11,8380 & 24,4185 & 21,0826 & 20,4675 & 16,1511 & 16,1511 \\
\hline 16 & Bali & 19,2023 & 10,5297 & 25,3598 & 23,3886 & 15,0211 & 20,1115 & 15,0211 \\
\hline 17 & Nusa Tenggara Barat & 8,4456 & 10,0895 & 27,8192 & 21,2689 & 24,1752 & 17,7539 & 17,7539 \\
\hline 18 & Nusa Tenggara Timur & 14,0070 & 13,5336 & 32,3904 & 25,4110 & 17,1057 & 25,1276 & 17,1057 \\
\hline 19 & Kalimantan Barat & 16,0679 & 11,0129 & 26,2958 & 20,1092 & 17,8409 & 17,9060 & 17,8409 \\
\hline 20 & Kalimantan Tengah & 19,9178 & 12,7428 & 25,3305 & 22,2356 & 14,0093 & 20,5742 & 14,0093 \\
\hline 21 & Kalimantan Selatan & 14,8464 & 10,9727 & 26,8760 & 20,6319 & 18,5437 & 18,0775 & 18,0775 \\
\hline 22 & Kalimantan Timur & 20,9379 & 13,5211 & 26,8550 & 22,7146 & 12,1443 & 22,5654 & 12,1443 \\
\hline 23 & Kalimantan Utara & 15,3698 & 9,0029 & 25,9828 & 19,7071 & 19,3283 & 16,7262 & 16,7262 \\
\hline 24 & Sulawesi Utara & 19,4282 & 6,9188 & 22,8298 & 18,5365 & 19,1124 & 15,9723 & 15,9723 \\
\hline 25 & Sulawesi Tengah & 13,8058 & 9,3120 & 25,3431 & 22,8304 & 19,9927 & 17,2063 & 17,2063 \\
\hline 26 & Sulawesi Selatan & 17,9456 & 9,0289 & 26,3153 & 24,0274 & 16,1510 & 20,1459 & 16,1510 \\
\hline 27 & Sulawesi Tenggara & 11,3707 & 6,8166 & 27,8044 & 18,7653 & 23,3009 & 16,4955 & 16,4955 \\
\hline 28 & Gorontalo & 13,2727 & 11,4663 & 26,0731 & 17,0513 & 21,2577 & 15,8741 & 15,8741 \\
\hline 29 & Sulawesi Barat & 13,1303 & 10,7653 & 27,1014 & 15,0427 & 22,1793 & 16,1470 & 16,1470 \\
\hline 30 & Maluku & 9,0148 & 8,2610 & 29,8018 & 23,0982 & 23,6121 & 20,0092 & 20,0092 \\
\hline 31 & Maluku Utara & 20,8264 & 8,8212 & 31,4883 & 25,1614 & 12,5953 & 25,7350 & 12,5953 \\
\hline 32 & Papua Barat & 15,0724 & 7,4663 & 23,1000 & 19,0316 & 21,4905 & 13,8212 & 13,8212 \\
\hline 33 & Papua & 14,4619 & 5,8184 & 21,6873 & 16,0418 & 24,3257 & 11,2749 & 11,2749 \\
\hline
\end{tabular}

TABEL 4

HASIL PROSES ITERASI -

\begin{tabular}{|c|c|c|c|}
\hline \multicolumn{4}{|c|}{ HASIL PROSES ITERASI - 1} \\
\hline NO & Provinsi & $\mathrm{c} 1$ & $\mathrm{c} 2$ \\
\hline 1 & Aceh & 1 & \\
\hline 2 & Sumatera Utara & 1 & \\
\hline 3 & Sumatera Barat & & 1 \\
\hline 4 & Jambi & 1 & \\
\hline 5 & Sumatera Selatan & & 1 \\
\hline 6 & Bengkulu & 1 & \\
\hline 7 & Lampung & & 1 \\
\hline 8 & Kepulauan Bangka & & 1 \\
\hline
\end{tabular}




\begin{tabular}{|c|c|c|c|}
\hline $\mathrm{NO}$ & Provinsi & $\mathrm{c} 1$ & $\mathrm{c} 2$ \\
\hline & Belitung & & \\
\hline 9 & Kepulauan Riau & 1 & \\
\hline 10 & DKI Jakarta & & 1 \\
\hline 11 & Jawa Barat & 1 & \\
\hline 12 & Jawa Tengah & & 1 \\
\hline 13 & DI Yogyakarta & 1 & \\
\hline 14 & Jawa Timur & & 1 \\
\hline 15 & Banten & & 1 \\
\hline 16 & $\begin{array}{l}\text { Bali } \\
\text { Nusa Tenggara }\end{array}$ & 1 & \\
\hline 17 & $\begin{array}{l}\text { Barat } \\
\text { Nusa Tenggara }\end{array}$ & & 1 \\
\hline 18 & Timur & 1 & \\
\hline 19 & Kalimantan Barat & 1 & \\
\hline 20 & Kalimantan Tengah & 1 & \\
\hline 21 & Kalimantan Selatan & & 1 \\
\hline 22 & Kalimantan Timur & 1 & \\
\hline 23 & Kalimantan Utara & & 1 \\
\hline 24 & Sulawesi Utara & & 1 \\
\hline 25 & Sulawesi Tengah & & 1 \\
\hline 26 & Sulawesi Selatan & 1 & \\
\hline 27 & Sulawesi Tenggara & & 1 \\
\hline 28 & Gorontalo & & 1 \\
\hline 29 & Sulawesi Barat & & 1 \\
\hline 30 & Maluku & & 1 \\
\hline 31 & Maluku Utara & 1 & \\
\hline 32 & Papua Barat & & 1 \\
\hline 33 & Papua & & 1 \\
\hline
\end{tabular}

Proses iterasi akan terus berlanjut sampai iterasi ke -3 sama dengan hasil proses pada hasil dari proses iterasi ke -n sama dengan iterasi kedua.Adapun centroid data dari hasil proses iterasi sebelumnya.Dalam proses iterasi ke -3 dan proses iterasi ke -3 penelitian ini proses iterasi berhenti pada serta hasil dari proses iterasi ke -3 dapat iterasi ke -3 dikarenakan hasil dari proses dilihat pada table 5,6, dan 7 berikut ini :

TABEL 5

CENTROID DATA ITERASI - 3

\begin{tabular}{ccccc}
\hline & $a$ & $b$ & $c$ & $d$ \\
\hline c1 & 21,1733 & 11,7462 & 28,0198 & 23,6086 \\
c2 & 14,4911 & 9,2070 & 24,5749 & 19,4037 \\
\hline
\end{tabular}


TABEL 6

PRoses ITERASI - 3

\begin{tabular}{|c|c|c|c|c|c|c|c|c|}
\hline \multirow[t]{2}{*}{ NO } & \multirow[t]{2}{*}{ Provinsi } & \multicolumn{4}{|c|}{$\begin{array}{c}\text { Proporsi Penduduk Berumur } 5 \text { Tahun ke Atas yang } \\
\text { Membaca (Baik Cetak Maupun Elektronik) Selama } \\
\text { Seminggu Terakhir menurut Provinsi, Jenis Bacaan, } \\
\text { dan Tipe Daerah, } 2018\end{array}$} & \multirow[b]{2}{*}{$\mathrm{c} 1$} & \multirow[b]{2}{*}{$\mathrm{c} 2$} & \multirow[b]{2}{*}{ jp } \\
\hline & & surat kabar & buku cerita & $\begin{array}{c}\text { pelajaran } \\
\text { sekolah }\end{array}$ & pengetahuan & & & \\
\hline 1 & Aceh & 29,7073 & 14,0153 & 29,2699 & 25,9120 & 9,2112 & 17,8620 & 9,2112 \\
\hline 2 & Sumatera Utara & 19,5214 & 11,1322 & 29,7892 & 23,9636 & 2,5223 & 8,7745 & 2,5223 \\
\hline 3 & Sumatera Barat & 13,8884 & 9,7352 & 25,0985 & 23,5887 & 8,1023 & 4,2930 & 4,2930 \\
\hline 4 & Jambi & 22,4544 & 9,8410 & 23,4542 & 21,8098 & 5,4178 & 8,4179 & 5,4178 \\
\hline 5 & Sumatera Selatan & 16,6058 & 8,4948 & 25,4152 & 20,2537 & 7,0336 & 2,5313 & 2,5313 \\
\hline 6 & Bengkulu & 18,3236 & 9,7531 & 29,1942 & 22,0459 & 3,9892 & 6,5807 & 3,9892 \\
\hline 7 & $\begin{array}{l}\text { Lampung } \\
\text { Kepulauan Bangka }\end{array}$ & 15,2539 & 8,1016 & 22,9609 & 17,1420 & 10,7579 & 3,0862 & 3,0862 \\
\hline 8 & Belitung & 19,1643 & 8,7687 & 20,8145 & 19,9087 & 8,8604 & 6,0354 & 6,0354 \\
\hline 9 & Kepulauan Riau & 20,3587 & 11,7139 & 29,2339 & 21,5592 & 2,5177 & 8,1893 & 2,5177 \\
\hline 10 & DKI Jakarta & 15,6598 & 7,5156 & 12,5742 & 13,2347 & 19,8616 & 13,6492 & 13,6492 \\
\hline 11 & Jawa Barat & 15,9530 & 11,4556 & 26,0086 & 20,8385 & 6,2493 & 3,3626 & 3,3626 \\
\hline 12 & Jawa Tengah & 13,3500 & 8,7576 & 23,8768 & 17,7853 & 11,0096 & 2,1473 & 2,1473 \\
\hline 13 & DI Yogyakarta & 30,8766 & 16,3217 & 27,5575 & 25,0740 & 10,8375 & 18,9776 & 10,8375 \\
\hline 14 & Jawa Timur & 16,9374 & 10,7777 & 24,1904 & 21,5292 & 6,1538 & 3,6217 & 3,6217 \\
\hline 15 & Banten & 13,2148 & 11,8380 & 24,4185 & 21,0826 & 9,0937 & 3,3755 & 3,3755 \\
\hline 16 & $\begin{array}{l}\text { Bali } \\
\text { Nusa Tenggara }\end{array}$ & 19,2023 & 10,5297 & 25,3598 & 23,3886 & 3,5340 & 6,3592 & 3,5340 \\
\hline 17 & $\begin{array}{l}\text { Barat } \\
\text { Nusa Tenggara }\end{array}$ & 8,4456 & 10,0895 & 27,8192 & 21,2689 & 13,0480 & 7,1646 & 7,1646 \\
\hline 18 & Timur & 14,0070 & 13,5336 & 32,3904 & 25,4110 & 8,7693 & 10,7760 & 8,7693 \\
\hline 19 & Kalimantan Barat & 16,0679 & 11,0129 & 26,2958 & 20,1092 & 6,4668 & 3,0343 & 3,0343 \\
\hline 20 & Kalimantan Tengah & 19,9178 & 12,7428 & 25,3305 & 22,2356 & 3,4187 & 7,1092 & 3,4187 \\
\hline 21 & Kalimantan Selatan & 14,8464 & 10,9727 & 26,8760 & 20,6319 & 7,1272 & 3,1698 & 3,1698 \\
\hline 22 & Kalimantan Timur & 20,9379 & 13,5211 & 26,8550 & 22,7146 & 2,3155 & 8,7369 & 2,3155 \\
\hline 23 & Kalimantan Utara & 15,3698 & 9,0029 & 25,9828 & 19,7071 & 7,7831 & 1,6994 & 1,6994 \\
\hline 24 & Sulawesi Utara & 19,4282 & 6,9188 & 22,8298 & 18,5365 & 8,8889 & 5,7800 & 5,7800 \\
\hline 25 & Sulawesi Tengah & 13,8058 & 9,3120 & 25,3431 & 22,8304 & 8,2447 & 3,5796 & 3,5796 \\
\hline 26 & Sulawesi Selatan & 17,9456 & 9,0289 & 26,3153 & 24,0274 & 4,5697 & 6,0310 & 4,5697 \\
\hline 27 & Sulawesi Tenggara & 11,3707 & 6,8166 & 27,8044 & 18,7653 & 11,9956 & 5,1272 & 5,1272 \\
\hline 28 & Gorontalo & 13,2727 & 11,4663 & 26,0731 & 17,0513 & 10,4539 & 3,7905 & 3,7905 \\
\hline 29 & Sulawesi Barat & 13,1303 & 10,7653 & 27,1014 & 15,0427 & 11,8266 & 5,4481 & 5,4481 \\
\hline 30 & Maluku & 9,0148 & 8,2610 & 29,8018 & 23,0982 & 12,7832 & 8,4767 & 8,4767 \\
\hline 31 & Maluku Utara & 20,8264 & 8,8212 & 31,4883 & 25,1614 & 4,8081 & 11,0104 & 4,8081 \\
\hline 32 & Papua Barat & 15,0724 & 7,4663 & 23,1000 & 19,0316 & 10,0345 & 2,3837 & 2,3837 \\
\hline 33 & Papua & 14,4619 & 5,8184 & 21,6873 & 16,0418 & 13,3244 & 5,5789 & 5,5789 \\
\hline
\end{tabular}


TABEL 7

HASIL PROSES ITERASI -3

\begin{tabular}{|c|c|c|c|}
\hline NO & Provinsi & $\mathrm{c} 1$ & $\mathrm{c} 2$ \\
\hline 1 & Aceh & 1 & \\
\hline 2 & Sumatera Utara & 1 & \\
\hline 3 & Sumatera Barat & & 1 \\
\hline 4 & Jambi & 1 & \\
\hline 5 & Sumatera Selatan & & 1 \\
\hline 6 & Bengkulu & 1 & \\
\hline 7 & $\begin{array}{l}\text { Lampung } \\
\text { Kepulauan Bangka }\end{array}$ & & 1 \\
\hline 8 & Belitung & & 1 \\
\hline 9 & Kepulauan Riau & 1 & \\
\hline 10 & DKI Jakarta & & 1 \\
\hline 11 & Jawa Barat & & 1 \\
\hline 12 & Jawa Tengah & & 1 \\
\hline 13 & DI Yogyakarta & 1 & \\
\hline 14 & Jawa Timur & & 1 \\
\hline 15 & Banten & & 1 \\
\hline 16 & Bali & 1 & \\
\hline 17 & Nusa Tenggara Barat & & 1 \\
\hline 18 & Nusa Tenggara Timur & 1 & \\
\hline 19 & Kalimantan Barat & & 1 \\
\hline 20 & Kalimantan Tengah & 1 & \\
\hline 21 & Kalimantan Selatan & & 1 \\
\hline 22 & Kalimantan Timur & 1 & \\
\hline 23 & Kalimantan Utara & & 1 \\
\hline 24 & Sulawesi Utara & & 1 \\
\hline 25 & Sulawesi Tengah & & 1 \\
\hline 26 & Sulawesi Selatan & 1 & \\
\hline 27 & Sulawesi Tenggara & & 1 \\
\hline 28 & Gorontalo & & 1 \\
\hline 29 & Sulawesi Barat & & 1 \\
\hline 30 & Maluku & & 1 \\
\hline 31 & Maluku Utara & 1 & \\
\hline 32 & Papua Barat & & 1 \\
\hline 33 & Papua & & 1 \\
\hline
\end{tabular}

Selanjutnya peneliti menggunakan bantuan software RapidMiner dalam proses pengujian penelitian ini.hasil proses pengujian dapat dilihat pada gambar 1,2,3, dan 4 berikut:

\section{Cluster Model}

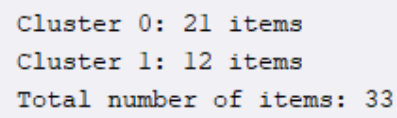

Gambar 1. Cluster Model Rapid Miner

TABEL 72.

CEnTROId DATA ITERASI - 3 RAPID Miner

\begin{tabular}{|l|l|l|}
\hline \multicolumn{1}{|c|}{ Attribute } & \multicolumn{1}{c|}{ cluster_0 } & \multicolumn{1}{c|}{ cluster_1 } \\
\hline surat kabar & 14.491 & 21.173 \\
\hline pengetahuan & 19.404 & 23.609 \\
\hline pelajaran sekolah & 24.575 & 28.020 \\
\hline buku cerita & 9.207 & 11.746 \\
\hline
\end{tabular}

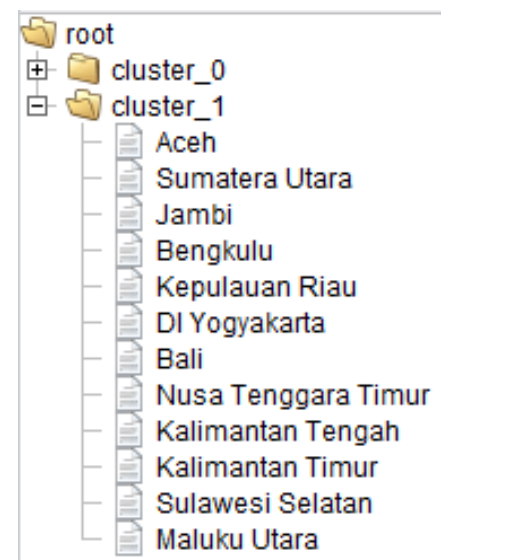

Gambar 2. Anggota Cluster tinggi (c1)

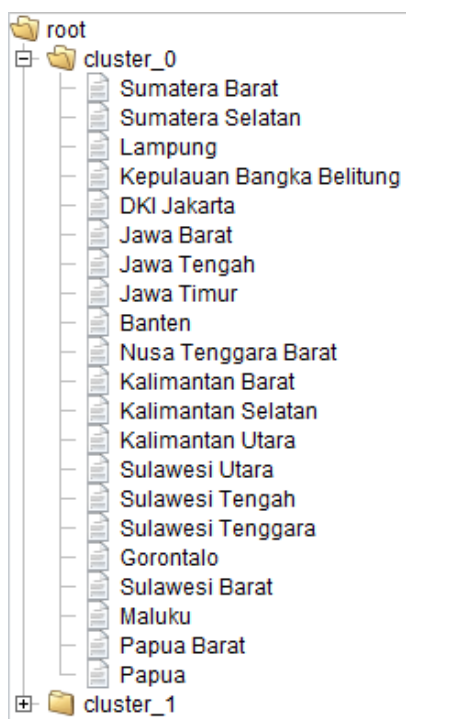

Gambar3. Anggota Cluster rendah (c2) 


\section{Kesimpulan}

Dengan menggunakan algoritma KMeans clushtering dapat menjadi salah satu pilihan terbaik dalam kasus mengelompokkan.Hasil dari penelitian ini menghasilkan -12 Provinsi clushter tingkat tinggi(C1) dan -21 Provinsi clushter tingkat rendah (C2).Dengan memanfaatkan software RapidMiner dapat menjadi salah satu pilihan terbaik dalam mengji hasil penelitian menggunakan algoritma K-Means clushtering. Diharapkan dengan dilakukan nya penelitiaan ini dapat menjadi masukan dan informasi kepada pemerintah setiap wilayah agar melakukan sosialisasi atau kegiatan yang dapat meningkat kan minat baca penduduk tiap wilayah terutama pada wilayah yang menduduki posisi tingkat rendah $(\mathrm{C} 2)$.

\section{Daftar Pustaka}

Farida, S. (2012). Faktor-Faktor Penyebab Keengganan Membaca. 321-327.

Iin Parlina, Agus Perdana Windarto, Anjar Wanto, M. R. L. (2018). Memanfaatkan Algoritma K-Means Dalam Menentukan Pegawai Yang Layak Mengikuti Asessment Center. Memanfaatkan Algoritma K-Means Dalam Menentukan Pegawai Yang Layak Mengikuti Asessment Center Untuk Clustering Program Sdp, 3(1), 87-93.

Metisen, B. M., \& Sari, H. L. (2015). Analisis clustering menggunakan metode $\mathrm{K}$ Means dalam pengelompokkan penjualan produk pada Swalayan Fadhila. Jurnal Media Infotama, 11(2), 110-118.

Sadewo, M. G., Windarto, A. P., \& Hartama, D. (2017). Penerapan Datamining Pada Populasi Daging Ayam Ras Pedaging Di Indonesia Berdasarkan Provinsi Menggunakan K-Means Clustering. InfoTekJar (Jurnal Nasional Informatika Dan Teknologi Jaringan), 2(1), 60-67. https://doi.org/10.30743/infotekjar.v2i1. 164 